\title{
Simultaneous projection and picture acqusition for a distributed collaborative environment
}

\section{Conference Paper}

Author(s):

Kunz, Andreas (D); Spagno, Christian

Publication date:

2002

Permanent link:

https://doi.org/10.3929/ethz-a-006042096

Rights / license:

In Copyright - Non-Commercial Use Permitted

Originally published in:

Proceedings / IEEE Virtual Reality 2002, https://doi.org/10.1109/VR.2002.996538 


\title{
Simultaneous Projection and Picture Acquisition for a Distributed Collaborative Environment
}

\author{
Andreas M. Kunz Christian P. Spagno \\ Swiss Federal Institute of Technology Zurich \\ Center of Product Development \\ kunz@imes.mavt.ethz.ch \\ cspagno@imes.mavt.ethz.ch
}

\begin{abstract}
Virtual Reality allows a simultaneous representation of three dimensional objects in different interconnected visualization installations [3]. This offers new possibilities for distributed collaborative work. Up to now the user remained mostly without consideration. But for an efficient distributed collaborative teamwork the user should be visualized three dimensionally together with other virtual objects [8]. A special projection installation is presented which allows simultaneous projection as well as picture acquisition of the person who uses the installation.
\end{abstract}

\section{Introduction}

Due to the increased dissemination of information technology in companies the need arises to use virtual reality in fields like product design. Today virtual reality is used to visualize geometries and complex calculation results.

First considerations arise not only to exchange virtual models between visualization installations as for example a $\mathrm{CAVE}^{\circledR}$ [4],[6], but also virtual images of the users [3]. The simultaneous representation of a virtual object and a person from the other unit does not make any problems [5]. On the other hand the simultaneous picture acquisition of a user and a continuous projection prepare major difficulties due to the following reasons:

- Bright and dark phases must be available almost synchronously. The bright stages are used during picture acquisition and the dark phases are used for projection [1].

- For a complete acquisition of the user's texture and silhouette he has to be continuously in the field of view of several cameras.

These above described problems occur in almost every high immersive system. In the presented poster a system is introduced by which the above problems can be eliminated. The new system allows to acquire the texture and silhouette of a person without lowering the immersion by the recognizable existence of disturbing cameras. The basic idea consists in placing the cameras behind the projection screen and outside of the beam paths of the projectors. The screen is switched between a translucent and an opaque state. During the opaque state of the projection screen the projection is visible while during the translucent state the cameras can capture the texture of the person inside the $\mathrm{CAVE}^{\circledR}$.

\section{Contributions}

The technical capabilities of existing $\mathrm{CAVE}^{\circledR}$ projection theatres is extended by the insertion of video cameras synchronized with the projection hardware. The envisioned system allows both to record life video streams of $\mathrm{CAVE}^{\circledR}$ users and to project virtual reality scenes simultaneously. Connecting multiple installations via a high-speed network allows remotely located users to meet, communicate and collaborate in virtual spaces.

The first setup integrates two LCD-projectors which are modified with external shutters. The cameras are camouflaged by electrically switchable glass and the user can not perceive the flash through the modified shutter glasses [1]. Additional electronic circuits produce the driving signals for the components. Next to the use of new materials the new principle is based on the implementation of a third time step in the active stereo projection. In this third step the whole picture acquisition takes place. During the third step both eyes are darkened by the shutter glasses and the active illumination takes place.

Through a sufficient brightness it is possible to carry out a satisfactory picture acquisition. The cameras which register the user's face have to be placed in front of him without being in his field of view [7]. Therefore the best position would be behind the projection screen where they can not be seen by the user. 
A solution for this is electrically switchable glass that can switch from opaque to transparent and vice versa when applying an electrical voltage. Without applying an electrical voltage the glass remains opaque but it turns transparent when a voltage is applied.

The cameras are placed on the backside of the screen and thus are not in the user's field of view. The cameras can look through the electrically switchable glass in the moment when the interior of the $\mathrm{CAVE}^{\circledR}$ is illuminated and both eyes of the user are darkened.

In order to avoid reflections of the projection on the backside of the projection screen and to prevent irritations of the cameras the projectors are provided with additional shutters that dim the projection exactly in the moment when the electrically switchable glass is translucent and the eyeglasses are darkened.

All active components of the overall system eyeglasses, flash, projection screen, shutters and cameras - are synchronized. The triggering of the components does not have to be synchronous with the image refresh rate of the computer which is responsible for the image generation.

The timing between the individual components is illustrated in the following figure:

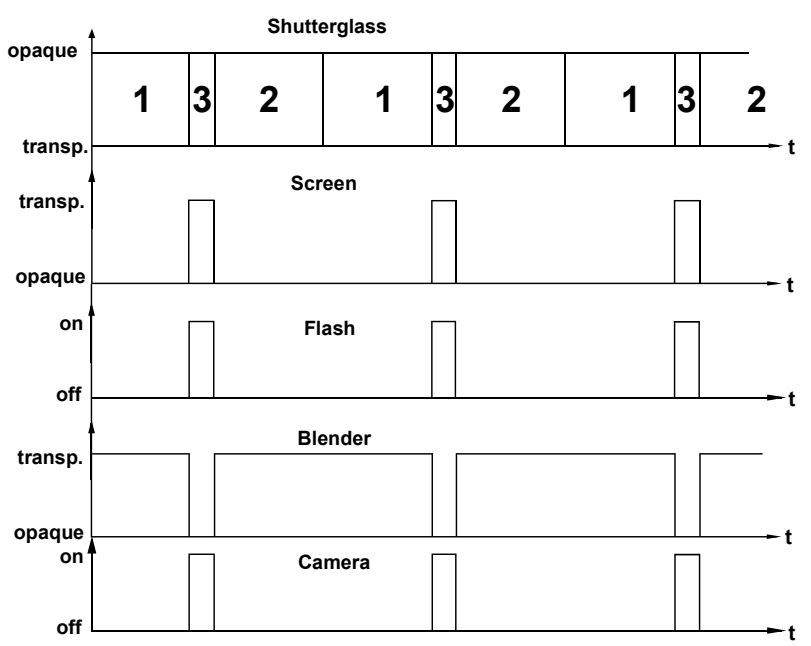

Figure 1. Timing diagram for the synchronous switching of the individual components

While the picture is being presented for the right or left eye (stages 1 and 2) no voltage is applied to the electrically switchable glass and thus it is opaque. The shutters in front of the projectors are switched transparent and no active illumination appears. As soon as both eyeglass are dark the screen is switched transparent, the shutters in front of the projectors become dark and the flash illumination is triggered. Simultaneously the picture acquisition takes place with the cameras. This takes place with a frequency of $60 \mathrm{~Hz}$ except for the camera which takes 15 pictures per second.

\section{Conclusions}

A new system was introduced that allows to carry out a simultaneous stereoscopic projection and picture acquisition without disturbing the user's immersion by the short-term illumination of the projection room. Through the selection of an electrically switchable projection material it is possible to camouflage the cameras for the picture acquisition so that they are not longer in the users field of view.

\section{References}

[1] Kunz, A.; Spagno, C.: "Novel Shutter Glass Control for Simultaneous Projection and Picture Acquisition" (PPT); Immersive Projection Technology and Virtual Environments 2001, pp. 257-266; May, 16-18 2001; Stuttgart (Germany); ISBN 3-211-83671-3; Springer-Verlag Wien/New York

[2] Gross, M.; Kunz, A.; Meier, M.; Staadt, O.: "The Blue-C: Integrating Real Humans into a Networked Immersive Invironment"; CVE Conference 2000;

[3] V.D. Lehner and T.A. DeFanti. „Distributed virtual reality: supporting remote collaboration in vehicle design." Computer Graphics \& Applications, 17(2): 13-17, 1997.

[4] C. Cruz-Neira, D.J. Sandin, and T.A. DeFanti, ,Surroundscreen projection-based virtual reality: The design and implementation of the cave." Proceedings of SIGGRAPH 93, pages 135-142, August 1993.

[5] R. Raskar, G. Welch, M. Cutts, A. Lake; L. Stesin, and H. Fuchs. „The office of the future: A unified approach to imagebased modeling and spatially immersive displays." Proceedings of SIGGRAPH 98, pages 179-188, July 1998.

[6] C. Cruz-Neira, D. J. Sandin, T. A. DeFanti, R. V. Kenyon, and J. C. Hart. „The cave: Audio visual experience automatic virtual environment." Communications of the ACM, 35(6): 6572, June 1992.

[7] H. Fuchs, G. Bishop, K. Arthur, L. McMillan, R. Bajcsy, S. Lee, H. Farid, and T. Kanade. „Virtual space teleconferencing using a sea of cameras." Technical Report TR94-033, The University of North Carolina at Chapel Hill, Department of Computer Science, 1994.

[8]] T. Disz, M. Papka, M. Pellegrino, and R. Stevens. „Sharing visualization experiences among remote virtual environments." In Proceedings of the International Workshop on High Performance Computing for Computer Graphics and Visualization, July 1995 